\title{
LETROZOLE IN THE TREATMENTOF PATIENTS WITH ADVANCED OR METASTATIC BREAST CANCER
}

\author{
Deyan Davidov, \\ Department of chemotherapy; Oncological center \\ Medical University, Pleven
}

\section{RESUME:}

Backgraund: Approximately $75 \%$ of breast cancers are hormone sensitive, and hormonetherapy is effective for many of these patients. The aim of this study is to evaluate the efficacy and safety of treatment with Letrozole in postmenopausal women with advanced or metastatic breast cancer. Methods: Thirty two postmenopausal women with histologically or cytologically proven breast cancer who presented with either locally advanced or had metastatic breast cancer, entered the study. Tumors were required to be estrogen or progesterone receptor positive. Therapy consists of Letrozole $1 \mathrm{mg}$ daily per os. Results: Thirty two patients were treated in Pleven Medical UniversityDepartment of chemotherapy. Three complete responses and seven partial responses were obtained. The main grade toxicity included rush and hot flushes. Conclusions: Letrozole was effective in patients with advanced or metastatic breast cancer with $38.2 \%$ response rate and mild to moderate toxicity.

Key words: Breast cancer, Letrozole, Survival

\section{INTRODUCTION}

Approximately $75 \%$ of breast cancers are hormonesensitive, and antiestrogen

therapy is effective for many of these patients. Tamoxifen is currently the most widely used endocrine therapy. In patients with advanced or metastatic breast cancer, appearance of resistance to Tamoxifen is common / 1/. Further endocrine therapy in these cases must rely on aromatase inhibitors to prevent the terminal step of aromatization in estrogen biosynthesis /2/. Letrozole is a newer, highly specific and potent non- steroid aromatase inhibitor. It lowers serum estrogen levels by inhibiting the peripheral conversion on androgens to estrogens $/ 3 /$. The source of estrogen, a growth promoter for many breast cancers, depends on a woman's menstrual status. In premenopausal women estrogens are of ovarian origin predominantly. In postmenopausal women estrogen primarily derive from conversion of circulating androgens to estrogens $/ 4 /$.

The aim of this study is to evaluate the efficacy and safety of treatment with Letrozole in postmenopausal women with advanced or metastatic breast cancer.

\section{PATIENTS AND METHODS}

Thirty two postmenopausal women with histologically or cytologically proven breast cancer who presented with either locally advanced or had metastatic breast cancer, entered the study. Tumors were required to be estrogen or progesterone receptor positive. All patients had relapse either while receiving continuos adjuvant antiestrogen therapy with Tamoxifen or within 12 months of stopping adjuvant antiestrogen therapy. Patients were permitted to have received at least one regimen of chemotherapy for advanced disease before Letrozole treatment. Patients were required to have at least one measurable and/or assessable tumor lesion. Patients were required to have discontinued any systemic anticancer treatment at the time of study entry. All patients were required to be postmenopausal as defined by one of the following criteria: women over 50 years of age who had not menstruated during the preceding 12 months, or women less than 50 years of age who had castrate follicle- stimulating hormone levels, or women who had undergone a bilateral oophorectomy. All laboratory results were required to be within the limits.

Letrozole (Femara; Novartis Pharma AG, Basel, Switzerland) was given per os at dose $2.5 \mathrm{mg}$ once daily in the morning.

Patients were evaluated for tumor response at 3 months after the start of therapy and then every 3 months thereafter. Tumor response was evaluated according to International Union Against Cancer criteria /5/.

Measurable disease was assessed either by palpation or on radiological assessment (x-ray, abdominal ultrasound, or computed tomography scan).

Response was defined as complete response (CR), partial response (PR), no change (NC), or progressive disease (PD).

A CR was defined by the disappearance of all known disease, confirmed by two observations not less than 4 weeks apart. PR was defined as a decrease in tumor size of $50 \%$ or more (either measured or estimated in the case of measurable or assessable disease). In addition, there could 
be no appearance of any new lesions or progression of any known lesion(s). Objective tumor response included both confirmed CR and PR. The duration of response was calculated from the day of the start of treatment to disease progression; overall survival was measured from study entry to death.

The time to disease progression was calculated from study entry until the day of the first evidence of disease progression.

Safety was assessed using the National Institutes of Health/National Cancer Institute common toxicity criteria / $6 /$.

\section{RESULTS}

A total of 32 patients were entered in the study over a 30- months period. Some patient's characteristics are listed in Table 1. All patients, regardless of their length of treatment, were included in analysis. Antitumour effects and safety of Letrozole were evaluated for all 32 cases. A median treatment period was 14,5 months. The median follow-up period was 17.3 months.

\section{Antitumour effects}

The resulting antitumour effects are presented in Table 2. The overall response rate /ORR/ was 48,4\% (15 of 32), showing that Letrozole had induced a significant efficacy. In addition, when stable disease (SD), which was defined as no change for 24 weeks or longer, was included in the rate, the response rates (clinical benefits) were $62,4 \%$ (20 of 32). Antitumour effects by dominant assessment sites are summarized in Table 3. ORR is higher in the patients with soft tissue lesions than the patients with other dominant assessment sites. ORR in the patients with soft tissue lesions was $63,6 \%$. Median time to tumour progression / TTP/ was 211 days. One- year survival rates were $87.5 \%$.

\section{Safety}

Table 4 presents the incidence of adverse drug reactions that occurred in entire group. The highest incidence was for rash, which was observed at 37,5\% in the patients. Most of these symptoms were rated as grade 1 or 2, except for one patient who developed grade 3 pruritus and rash. Only one patient suffered grade 4 cardiac arrest in group and this individual had a history of Farmorubicin treatment. One patient had genital bleeding. Abnormal values for laboratory tests related to hepatic function were observed such as elevation of alkaline phosphatase, ASAT, ALAT.

\section{DISCUSSION}

Since aromatase inhibitors exert their pharmacological actions through a mechanism, which differs from that of conventional antiestrogenic agents such as tamoxifen, they are expected to be effective in the treatment of antiestrogen resistant breast cancer /7/. Letrozole, a highly potent and specific third-generation aromatase inhibitor, has been approved for use in second- line therapy for advanced breast cancer. This is due to results obtained from large clinical trials comparing Letrozole with other similar agents, as Medroxiprogesteroneacetat /MA/, or Aminoglutethimide /AG/, a first-generation aromatase inhibitor, which have shown the superiority of Letrozole over MA or AG /8/.

We conducted a study to evaluate the clinical efficacy of Letrozole in patients with advanced breast cancer. Our data showed that Letrozole was effective in-patients who had received prior treatment with an antiestrogen. These response rates demonstrated the consistently superior efficacy of Letrozole in advanced/relapsed breast cancer. When ORR were stratified by sites of assessment, it was $62.6 \%$ in the Letrozole -treated patients with metastatic lesions in soft tissue, which could be an advantage, as metastasis of breast cancer frequently occurs in soft tissues such as lymph nodes and skin. The median time that required for achieving efficacy was short- 78 days, indicating that Letrozole is thus more appropriate for treating breast cancer in the clinical setting.

The incidence of adverse drug reactions was $37.5 \%$. Gastrointestinal and skin symptoms were the main adverse drug reactions observed in the Letrozole treatment. Increases in parameters of hepatic factors were observed in the group, but these were not serious. The results showing high tolerability for Letrozole suggest that Letrozole could have higher therapeutic efficacy than other conventional aromatase inhibitors.

Table 1. Patient characteristics [means \pm standard deviation (SD)] or number of patients

\begin{tabular}{|l|l|}
\hline Patient characteristics & $\begin{array}{l}\text { means } \pm \text { SD or number } \\
\text { of patients }\end{array}$ \\
\hline Age (years) & $58.7 \pm 1.83$ \\
\hline Height $(\mathrm{cm})$ & $162.1 \pm 2.6$ \\
\hline Weight $(\mathrm{kg})$ & $66.5 \pm 2.9$ \\
\hline Dominant site of metastasis & \\
Soft tissue & $12(37.5 \%)$ \\
Bone & $6(18,7 \%)$ \\
Viscera & $14(43.7 \%)$ \\
\hline No. of evaluable lesions & \\
1 & $17(53.1 \%)$ \\
2 & $11(34.3 \%)$ \\
23 & $4(12.5 \%)$ \\
\hline
\end{tabular}




\begin{tabular}{|l|l|}
\hline Receptor status & $13(40.3 \%)$ \\
$\operatorname{ER}(+)$ and $\operatorname{PgR}(+)$ & $19(18.2 \%)$ \\
$\mathrm{ER}(+)$ or $\operatorname{PgR}(+)$ & $21(63.9 \%)$ \\
\hline Performance status & $10(32,5 \%)$ \\
0 & $1(3.2 \%)$ \\
1 & \\
2 & $23(71.8 \%)$ \\
\hline Prior therapy & $9(28.2 \%)$ \\
Adjuvant only & $14(43.7 \%)$ \\
Therapeutic \pm adjuvant & $18(56.3 \%)$ \\
\hline Prior antiestrogen therapy & \\
Adjuvant only & $3(9.1 \%)$ \\
Therapeutic \pm adjuvant & $29(90.9 \%)$ \\
\hline Diagnosis & $7(21.6 \%)$ \\
Advanced breast cancer & $14(44.6 \%)$ \\
Recurrent breast cancer & $8(24.3 \%)$ \\
\hline Disease-free interval & $3(9.5 \%)$ \\
$<2$ years & \\
2-5 years & \\
5-10 years & \\
$\geq 10$ years & \\
\hline
\end{tabular}

Table 2. Objective responses

\begin{tabular}{|l|c|c|c|c|c|c|}
\hline $\begin{array}{l}\text { Patients/ } \\
\text { Response }\end{array}$ & CR & PR & SD & NC & PD & ORR\% \\
\hline 32 & 3 & 7 & 5 & 5 & 12 & $62,4 \%$ \\
\hline
\end{tabular}

$\mathrm{ORR}=\mathrm{CR}+\mathrm{PR}+\mathrm{SD}(24$ weeks $\mathrm{NC})$.

$\mathrm{CR}$, complete response; PR, partial response; SD, stable disease; NC, no change; $\mathrm{PD}$, progressive disease; ORR, overall objective response rates;

Table 3. Objective response (dominant assessment site)

\begin{tabular}{|l|c|c|c|c|c|c|}
\hline $\begin{array}{l}\text { Dominant site/ } \\
\text { Response }\end{array}$ & CR & PR & SD & NC & PD & ORR $\%$ \\
\hline Soft tissue $(n=11)$ & 2 & 4 & 0 & 1 & 4 & $63,6 \%$ \\
\hline Bone $(n=12)$ & 1 & 3 & 2 & 2 & 5 & $66,7, \%$ \\
\hline Viscera $(n=8)$ & 0 & 0 & 3 & 2 & 3 & $37,5 \%$ \\
\hline
\end{tabular}

$\mathrm{CR}$, complete response; $\mathrm{PR}$, partial response; $\mathrm{SD}$, stable disease NC, no change; PD, progressive disease; ORR, overall objective response rates;

Table 4. Adverse drug reactions by symptoms: number of patients Letrozole-treated $\quad(n=32)$

\begin{tabular}{|l|l|}
\hline Adverse drug reactions & Number of patients \\
\hline Nausea & $7(21,8 \%)$ \\
\hline Vomiting & $6(18,7 \%)$ \\
\hline Anorexia & $4(12,5 \%)$ \\
\hline Headache & $7(21,8 \%)$ \\
\hline Rash & $12(37,5 \%)$ \\
\hline Hot flushes & $13(40,6 \%)$ \\
\hline Genital bleeding & $2(6,2 \%)$ \\
\hline Sinus arrest & $1(3,2 \%)$ \\
\hline Pruritus & $1(3,2 \%)$ \\
\hline
\end{tabular}

\section{REFERENCES}

1. Dowsett M. Overexpression of HER- 2 as a resistance mechanism to hormonal therapy for breast cancer. Endocr- Relat. Cancer 2001, 8,191 - 195

2. Goss PE, Strasser K. Aromatase inhibitors in the treatment and prevention of breast cancer. J Clin Oncol 2001, 19, 881 $-894$

3. Bhatnagar AS, Hausler A, Schieweck $\mathrm{K}$, et al: Highly selective inhibition of estrogen biosynthesis by CGS 20267, a new nonsteroidal aromatase inhibitor. J Steroid Biochem Mol Biol 37:1021-1027,
1990

4. Miller, W. R. Aromatase inhibitors in breast cancer. Cancer Treat. Miller, W. R. Aromatase inhibitors in breast cancer. Cancer Treat. Rev., 23: 171-187, 1997.

5. Rose C., Vtoraya O., Pluzanska A. et al; An open randomized trial of secondline endocrine therapy in advanced breast cancer: comparison of the aromatase inhibitors letrozole and anastrozole. Eur J Cancer, 39; 401-410, 2003

6. Common Toxicity Criteria: National Institutes of Health. Cancer Therapy
Evaluation Program, Division of Cancer Treatment, Bethesda, MD, 1993

7. Roseman BJ, Buzdar AU, Singletarffy SE. Use of aromatase inhibitors in postmenopausal women with advanced breast cancer. J Surg Oncol1997; 66: 215-220.

8. Dombernowsky P, Smith I, Falkson $\mathrm{G}$ et al. Letrozole, a new oral aromatase inhibitor for advanced breast cancer: double-blind randomized trial showing a dose effect and improved efficacy and tolerability compared with megesterol acetate. J Clin Oncol 1998; 16: 453-461.

Address for correspondence: Deyan Nikolov Davidov

Department of Chemotherapy, Oncological Center, University Hospital - Pleven, 8A, Georgy Kochev Str., 5800 Pleven, Bulgaria

Tel.: +359/64/886 317; Fax: +359/64/831634;

E-mail: dean_davidov@abv.bg; 